\title{
CRAIG MORRIS EN TRES TIEMPOS
}

\section{TIEMPO I}

\section{Proyecto Arqueológico-Histórico Chincha-Pisco}

Cuando yo era un joven estudiante del entonces Programa de Arqueología de la Universidad Nacional Mayor de San Marcos, intentaba colocarme como muchos de mis compañeros en cuanto proyecto arqueológico existiese sin ir en desmedro de nuestros estudios y otras actividades académicas; en el año 1985 pretendí junto con un amigo (C. Roldán Del Águila) participar en un proyecto en Nasca, y en el ínterin nos quedamos una noche con la gente del Proyecto Arqueológico-Histórico Chincha-Pisco que tenía una característica especial y novedosa para la época; era un proyecto multidisciplinario en que se engarzaban disciplinas como la arquitectura, la antropología, y la botánica, la zoología entre otras, en dos ejes helicoidales, la Historia y la Arqueología como disciplinas de la Ciencia Social.

En esa época el proyecto tenía como representantes al doctor Luis Guillermo Lumbreras y el doctor Craig Morris; ellos dirigían desde cada valle mencionado la parte correspondiente. El primero ya lo conocíamos como uno de los más renombrados profesores de la Universidad Nacional Mayor de San Marcos y del segundo no lo conocía personalmente sólo sabía que era miembro de un museo en Nueva York, el American Museum of Natural History, que había trabajado en Huánuco Pampa y que había planteado algunas hipótesis sobre el dominio inka imperial y su representación fuera de Cusco; amén de ello había participado en el recorrido del camino inka; también que era uno de los principales gestores económicos del mentado proyecto.

Ya más formados, y con mucha osadía, participamos en dicho proyecto en el año 1987 donde el componente de Arqueología se concentró básicamente en La Centinela y en los montículos Paracas en el valle de Chincha, cerca de la población de El Carmen, el sitio de El Mono o de Chococota como se le llamó más tarde. Al igual que en la temporada del año 1985 los codirectores más conspicuos fueron el doctor Lumbreras que dirigió la campaña personalmente y vi, en una visita fugaz, al doctor Morris quién me pareció una persona tan ocupada que prácticamente saludó, hizo unas cuantas preguntas y se retiró con la plana mayor para seguir discutiendo temas relacionados con los proyectos.

Lo vi, más adelante unas cuantas veces, como cuando organizamos una parrillada para recaudar dinero para continuar con una investigación institucional y lo vi de forma efímera pero cordial; así como también en el homenaje que el Instituto Andino de Estudios Arqueológicos realizó in memorian de John Hyslop con la publicación en castellano sobre el viario imperial del Tawantinsuyu, que sirvió de texto base para la creación del famoso programa Qhapaq Nan del estado peruano. 


\section{TIEMPO II}

\section{Programa de Investigaciones Arqueológicas Chincha}

Ya menos jóvenes formamos el Programa de Investigaciones Arqueológicas Chincha, el PIA$\mathrm{CH}$ para los amigos, con una mayor amplitud de conocimientos y años de experiencia en conjunto dirigimos diversos proyectos en el marco del Programa.

Para entonces contábamos el apoyo directo de Lumbreras y Craig reconociéndonos como las personas jóvenes pero capaces de dirigir nuestros propios proyectos con nuestras hipótesis y tesis entorno al manejo de recursos económicos en el valle, su administración, el manejo del espacio, manejo y expresión física de las relaciones sociales y del poder entre otras cosas, y de las formas más interdisciplinarias que podíamos.

Al principio de dichas campañas, su apoyo académico y económico era sustancial para nuestro programa, en su calidad humana aun lo percibíamos como un colega decidido, y aun nos daba sorpresas como luego averiguamos que no todos los fondos económicos provenían del Museo en que trabajaba sino de sus ahorros y parte de su sueldo, esta magnamidad se encontraba en directa proporción con su jovial timidez. Esa timidez fue poco a poco desapareciendo ante nuestros ojos, y pronto nos encontrábamos almorzando con mis compañeros y con el profesor Santillana construyendo y destruyendo hipótesis, formulando nuevas estrategias de campo y recolección de información, y de pronto no sólo le escuché reír sino también contar anécdotas y hacer bromas; fue en esos momentos que completé la idea del científico y del ser humano en un solo cuerpo, en ese alto, delgado y desgarbado cuerpo.

En Lima tuvimos una serie de reuniones donde la nota curiosa se daba en que siempre tomábamos té en diferentes tazas, ninguna, nunca era una taza igual que otra, y es una de las pocas cosas que nunca le pregunté, y nunca tendré respuesta quizás.

Al poco tiempo asumí la Dirección General de Patrimonio Arqueológico del Instituto Nacional de Cultura, y tuve que dejar mi puesto como investigador del programa que ayudé a construir; pero eso no impidió que por un lado se usase la estructura del programa como modelo para el actual Reglamento de Investigaciones; y por el otro lado, la amistad nunca se dejó en cuenta y cada vez que la oficialidad quedaba de lado salía a relucir la amistad, y las reuniones de té entre amigos continuaba.

Renuncié por enésima vez al Instituto Nacional de Cultura, me fui a hacer una maestría fuera del país, y retorné a trabajar en dicha institución estatal. Me involucré en dos proyectos del Instituto formando una oficina de información corporativa para el servicio del público en general la cual fue saboteada por razones que no vienen al caso, y la otra, después, en la conducción de la Coordinación General de las Curadurías del Museo de Arqueología, Antropología e Historia del Perú que dirigía mi amigo señalado en el primer párrafo de este proemio. Desde esa actividad laboral tuvimos contacto con Craig como ya era costumbre entre amigos, y nos comentó que pensaba hacerse una cirugía al corazón ni bien regresase a Nueva York, aprovechando un descanso.

Un día de junio, un soleado 14 de junio de 2004, falleció Craig Morris y poco tiempo después nos enteramos con espanto y desazón de la muerte de nuestro amigo. Se intentó hacer algunas cosas en su honor y memoria pero poco se pudo hacer pues a mi colega le sacaron de su puesto como director y yo fui 'renunciado' por una jugada que nunca entenderé, y tampoco quiero explicaciones. 


\section{TIEMPO III}

\section{HOY DÍA, NUEVAS PERSPECTIVAS}

Con el tiempo transcurrido entre su fallecimiento, la frustración del primer intento, y actividades alternas a nuestros propios trabajos decidimos conjugar nuevamente intereses y ejecutar acciones concretas para recordar y partir de ahí con nuevas cosas como hubiese querido.

Una de ellas es el Coloquio Homenaje a Craig Morris 2010, entre el 14 y 18 de junio en conmemoración de su fallecimiento tocando diversos ejes temáticos. Dicha reunión ha sido coorganizada por el Centro Cultural de la Universidad Nacional Mayor de San Marcos, Wamani, Sofía Chacaltana y el Museo de Arqueología y Antropología de la Universidad Nacional Mayor de San Marcos. Espero personalmente que este homenaje se convierta en un programa de investigaciones continua con reuniones constantes de evaluaciones e intercambio de información; y con publicaciones periódicas en este mismo espacio, en nuestra revista que ha cumplido cuarenta años, Arqueología y Sociedad.

Y por otro lado, como actividad propia del museo se ha realizado una feliz convocatoria de notas y artículos sobre temas que hubiera compartido Morris para esta fecha; en esta edición de Arqueología y Sociedad hay nuevos artículos y algunos otros son reediciones que son interesantes e importantes de divulgarlos por este medio; basta decir que algunos están relacionados a la presencia imperial o Tawantinsuyu y su expresión concreta y directa que podemos recoger desde la etnohistoria y la arqueología, así como los trabajos relacionados a la ocupación humana en Chincha, los manejos del espacio y el impacto en la producción, y la reproducción, de los Chincha con respecto a la alianza que establecieron los señores de Chincha con los Inkas.

Me imagino que si estuviera vivo Morris, estaría leyendo estos artículos mientras toma una caliente taza de té que le empañaría sus lentes, masticando unas galletas de agua compradas en el mercado modelo de Chincha; o quizás en un rincón umbroso del Salón General, enfundado en su traje mientras sonríe tímidamente escuchándonos hablar de él o de los temas que le interesaban.

Para cerrar este proemio, quisiera recordar parafraseando al doctor Tello, que lo más importante de todo no es el objeto mueble como un ceramio Chincha o un inmueble como Tambo Colorado, sino que lo más importante es saber de la persona, a la sociedad a la que pertenecía, incluyendo la expresión particular de la misma que llamaremos cultura. Saber que un tipo de sociedad fue capaz de hacer tales cosas hasta niveles increíbles, es saber cómo las sociedades enfrentaron sus retos y buscaron soluciones en aquellos momentos; es saber sobre todo que nosotros podemos hacer cosas grandes frente a nuestros propios retos y futuro en el marco de nuestra continua formación de la Identidad Histórica Nacional.

Y creo firmemente que trabajando interdisciplinariamente y difundiendo el conocimiento enmarcado en la humildad científica será el mejor homenaje que podamos brindar a un colega, a un científico, a un amigo como Craig Morris.

Con BB.BB.VV.

Arqueólogo Fernando Federico Fujita Alarcón

Director del Museo de Arqueología y Antropología

Universidad Nacional Mayor de San Marcos 